\title{
The ethics of organ transplantation: how comprehensive the ethical framework should be?
}

\author{
Mohammed Ghaly
}

Published online: 17 January 2012

(C) The Author(s) 2012. This article is published with open access at Springerlink.com

\section{Introductory remarks}

Organ transplantation is one of the major medical achievements of the twentieth century (Mancuso 2006:138). The discovery of effective immunosuppressive drugs in the late 1970s was an important step towards increasing the success rate of organ transplants and thus paved the way for organ transplantation to become a medical routine affair in the twenty-first century (Schmidt 2003: 319). The current prevalence of organ transplantation was clearly to see in a recently published study which assembled worldwide data on living kidney transplantation. The study showed steady rise of living kidney transplantation in most regions of the world. According to statistics given by this study, "The number of living kidney donor transplants grew over the last decade, with $62 \%$ of countries reporting at least a $50 \%$ increase. The greatest numbers of living donor kidney transplants, on a yearly basis, were performed in the United States (6435), Brazil (1768), Iran (1615), Mexico (1459), and Japan (939). Saudi Arabia had the highest reported living kidney donor transplant rate at 32 procedures per million population ( $\mathrm{pmp}$ ), followed by Jordan (29), Iceland (26), Iran (23), and the United States (21)" (Horvat et al. 2009:1088).

When a medical treatment, like organ transplantation, becomes so prevalent and manages to achieve impressive success rates in improving the quality of patients' lives worldwide then intriguing ethical questions will be raised by default. The main thesis of this thematic issue is that the ethical framework of organ transplantation should be as

M. Ghaly $(\bowtie)$

Faculty of Humanities, Leiden University, Leiden,

The Netherlands

e-mail: m.ghaly@religion.leidenuniv.nl comprehensive as possible and thus should not be confined to conventional set of ethical questions related to the donor-recipient relationship. The first article in this thematic issue argues that media ethics should be incorporated in this ethical framework. The second article asks for more critical consideration to the requirement of consent, which underlines the authority of people in regard to their bodies. The third article speaks of a need to offer pyschological care to the living kidney transplantation partners before and after transplantation. The fourth and fifth articles elaborate on the need to involve the religious aspects in the ethical discourse on organ donation.

\section{The articles in focus}

In the first article, "Mass media campaigns and organ donation: managing conflicting messages and interests", Mohamed Rady, Joan McGregor and Joseph Verheijde examine mass media campaigns launched in the Unites States, specifically at the local offices of the states' department of motor vehicles (DMV), meant to "promote citizens' willingness to organ donation and donor registration". On one hand, the authors recognize the significance and also the success of such campaigns to mobilize public awareness about organ donation and also to increase the numbers of registered donors. On the other hand, they raise serious ethical concerns about the work-method of these media campaigns. One of these concerns has to do with impartiality and scientific accuracy which the authors miss in these media campaigns especially when these campaigns communicate information about the concept of brain death. According to the authors, there is even no certainty that the DMV officials are well-acquainted with medical, scientific and religious controversies related to 
determining death for transplantation. Another ethical concern relates to the possible conflict of interests in providing care for both patients and potential donors. Media campaigns sometimes do not even recognize such potential conflict of interests. The authors argue that paying no attention to this possible conflict of interests and just labeling it as myth can transform the process of acute hospital care from "caring for patients" to "caring for organs". At the end, the authors argue, public media campaigns should "demand the highest standard of transparency and accuracy of information related to healthcare issues so as to enable the general public to make informed decisions about health and lifestyles". In order to overcome these ethical concerns and rehabilitate the ethical image of these media campaigns, the authors propose five practical guidelines: "(1) media campaigns should communicate accurate information to the general public and disclose factual materials with the least amount of bias; (2) conflicting interests in media campaigns should be managed with full public transparency; (3) media campaigns should disclose the practical implications of procurement as well as acknowledge the medical, legal, and religious controversies of determining death in organ donation; (4) organdonor registration must satisfy the criteria of informed consent; (5) media campaigns should serve as a means of public education about organ donation and should not be a form of propaganda" (Rady et al. 2012).

In the second article, "The role of the relatives in opt-in systems of postmortal organ procurement", Govert den Hartogh also elaborates on the concept of consent but from a different angel. Respecting the decision of the deceased person, whether in favor of or against organ donation, is a common starting point for the different legal systems which regulate the procurement of postmortal organs for transplantation. However, opt-in systems used to claim a higher respect for the requirement of consent than the opt-out systems. When no legally valid decision of the deceased was registered, then opt-in systems do not allow procuring the deceased's organs because of the absence of actual consent. However, opt-out systems allow harvesting the organs because of the absence of actual rejection from the side of the deceased. Den Hartogh argues that the claim of the opt-in system about respecting consent cannot be ethically justified when it concerns authorizing the deceased's family in almost all opt-in systems to decide if the deceased has not made a decision about donation. How this can be reconciled with one's right to make decision concerning one's dead body? The article reviews and refutes three possible justifications for tolerating this decision power of the deceased's family. The first justification is the presumed delegation. This means that it will be presumed that the deceased, who did not make decision about organ donation, consent to the decision to be made by the family. In response, Den Hartogh underscores that all what can be presumed in this specific case is only preference and preference is not consent. He adds that the legal situation is even much more vulnerable to critique regarding this point. The second possible justification is that the deceased's family will be donors by procuration. Family is supposed to decide in the spirit of the deceased and thus take the decision they believe that $\mathrm{s} / \mathrm{he}$ would have made. To the author, this idea of proxy decision-making is highly problematic for different reasons. One of these reasons is that there is no guarantee that the decision of the deceased's family will be determined by other factors which might have nothing to do with deciding in the spirit of the deceased. The third proposed justification is that the deceased's family enjoys independent authority in this regard and thus has the right to decide about their deceased's organs if s/he did not make decision. The proponents of this justification maintain that decision-making even in the context of individualistic society is always a collective process where consultation with one's relatives is usually indispensable. It is specifically this group, viz. family, which will make the final decision after the demise of the concerned person who was supposed to make such a decision but $\mathrm{s} / \mathrm{he}$ did not. Again Den Hartogh does not find this justification convincing. One of his counterarguments to this justification reads, "A recognition of the social embeddedness of 'autonomous' agents does not commit one to hold only families and other groups to be empowered to make decisions regarding those agents". Finally, the author concedes that he cannot find any convincing moral justification to give such an authority to the deceased's family. Bearing in mind the current reality concerning the procedures of organ donation and transplantation, the author concedes that he will regretfully permit doctors to stick to the deceased's family veto to donate his/her organs if the family has "strong insurmountable objections to it". As a step forward, the article also proposes specific legal amendments to make the opt-in system more compatible with the requirement of consent (Den Hartogh 2012).

In the third article, "Narratives: an essential tool for evaluating living kidney donations", Anne Alnaes presents the results of her anthropological fieldwork, which took 36 months, on living kidney donation in Norway. In the same vein of critique previously outlined by Mohamed Rady et al., Alnaes speaks of less positive aspects of organ transplantation which appear less frequently or are sometimes completely missing in the media coverage of transplantation stories and public donation campaigns. In a bid to fill in this lacuna, the article examines three case studies and analyzes them according to narrative theory where the transplantees' frustrations and worries are also highlighted. The first case study is about a sister "Sissel" who donated her kidney to her brother "Arne" in order to improve the 
quality of his life. After the transplantation, Arne started to suffer serious infection in the kidney donated by his sister because of his "underlying disease" about which he had no knowledge before the kidney transplantation. Instead of returning back to normal life which he hoped, Arne will possibly undergo another round of renal replacement therapy. Had he known of this "underlying disease", Arne commented, he would have never gone for the option of living kidney donation from his sister but would have rather waited for deceased donation. On the other hand, Sissel said that she does not experience the same regret and stressed that she would always have made the same decision. However, Sissel suffered from the feeling of helplessness and grief on different occasions in the past where people who are near and dear to her feel ill or died without being able to reverse the course of events. In the case of her brother, she felt that she could do something this time. The question, however, remains what her feelings would be if her donated kidney ultimately did not succeed to save her brother's life or at least to improve its quality. The second case relates the story of "Ayesha" the Norwegian born Asian girl who donated her kidney to her sick sister. Ayesha had uneasy relationship with her family and she was even estranged from her most relatives to the extent that they would overlook her in the street. It seems that Ayesha hoped that donating her kidney to her sister might help her restore this relationship. However, this did not work out and she became even more disappointed in her family. Ayesha also thought she might be entitled to a gift from society because she "had indirectly saved the public health care system the expenditure of maintaining her sister on dialysis". She expressed her desire to undergo plastic surgery to improve her figure and hoped that the Norwegian public health care system might fund this surgery as a sort of repaying her favor, namely donating her kidney. Ayesha came to know that she is not entitled to such "counter-gift" from society, something which might have added to her pessimism and frustration. The third study case is about Karl who donated his kidney to his sick brother Daniel. This case had unexpected dramatic consequences. Just 2 days after the transplantation, Karl came to know that he got fatal bilateral lung embolisms. This news generated feelings of anguish and grief especially among the two brothers' spouses. Also Daniel, the recipient, spoke about feelings of guilt and being responsible for his brother's critical condition. However, Karl expressed no regrets for having donated his kidney to his brother. After revealing different cognitive and emotional aspects of these three telling stories, the author concludes that professional psychologists should be consistently involved in the preand post-transplantation process (Alnaes 2012).

In the fourth article, "Religious attitudes towards living kidney donation among Dutch renal patients", Sohal Ismail et al. reflect upon living kidney donation among patients of non-European origins living in the Netherlands and to what extent religion can play a positive or negative role in their vision about organ donation. The article let people themselves speak and tell what they think the standpoint of their religion is towards organ donation. This study was based on focus group discussions and in-depth interviews conducted with fifty patients and then analyzed in the Atlas.ti software package using the principles of Grounded Theory. As for the religious affiliations and ethnic backgrounds, nineteen of the interviewed patients were Muslims and had Moroccan, Turkish and Surinamese backgrounds. Seventeen patients with Surinamese, Antillean and Cape Verdean backgrounds were Christians. Four Surinamese patients were Buddhist and three Dutch patients were identified as atheist. Almost all interviewed patients opined that their religion is in favor of living kidney donation. To the patients, this positive attitude adopted by their religion towards organ donation was mainly because religion cherishes two main ethical values, namely helping others and saving people's lives whenever possible. The interviewees also conceded that their positive understanding of religion concerning organ donation is not necessarily shared by all members of their ethnic or religious communities. They spoke about religious objections which circulate in these communities. For instance, Turkish and Moroccan patients spoke about bodily integrity and that Muslim should, physically speaking, be complete by death and should enter the grave whole. A Turkish patient added another possible objection. Some Muslims think that organ transplantation creates blood relationship between the organ donor and the recipient, something which will be problematic if the donor happens to be non-Muslim or nonbeliever. To the interviewed patients, such objections are baseless from religious perspective. For instance, one of the Turkish patients, who is also an imam, said that he always clarifies such misunderstandings in his speeches in the mosque. Another Turkish patient spoke about the positive attitude adopted by the imam he knows towards organ donation. "The imam has clearly said you can be a donor. If the Imam says it can then it is ok", the Turkish patient argued. The interviewed patients found it unfortunate that there is no sufficient awareness about the significance of this issue and that many persons in these communities are unaware of the exact standpoint of their religion towards organ donation. Some of the interviewees also added that varying interpretations of Holy Scriptures are common in their communities and this makes people confused and divided about this issue. The authors conclude this article by calling for more attention to and conducting more studies on organ donation with respect to religion in order to better understand the ethnic minorities. They also recommend that physicians get more acquainted 
with the potential religious barriers against organ donation (Ismail et al. 2012).

In the fifth article, "Religio-ethical discussions on organ donation among Muslims in Europe: an example of transnational Islamic bioethics", Mohammed Ghaly sheds light on the discussions among Muslim religious scholars on organ donation as far as this issue particularly relates to Muslims living in Europe. The article examines three main religious guidelines (fatwas) issued respectively by the UK Muslim Law (Shariah) Council in 1995 in the UK, the European Council for Fatwa and Research (ECFR) in 2000 in Ireland and the Moroccan religious scholar Mustafa Ben Hamza during a conference on "Islam and Organ Donation" held in March 2006 in the Netherlands. The three fatwas compose part of the nascent field of study generally known as "Islamic Bioethics". This field studies the religioethical discourse of Muslim religious scholars who try to formulate Islamic perspectives on ethical questions raised by biomedical advancements. The first fatwas relevant to organ donation in particular date back to the second half of the twentieth century and the following decades witnessed a "storm of fatwas" on this issue. However, almost all these fatwas exclusively focused on the situation in the Muslim world. The three fatwas studied in this article show that by the end of the twentieth century Muslim religious scholars started to specifically address Muslims in Europe. The article shows that the socio-political context in which these fatwas were issued was highly negative. Different (semi)official reports and sometimes also European politicians depicted Muslims living in Europe as people who are not willing to donate their organs and some of them justify this standpoint on religious grounds. The three fatwas examined in this article shared one main purport; organ donation is in principle permitted in Islam. The fatwa issued by the ECFR in 2000 copiously quoted the pro-organ donation fatwas issued earlier in the Muslim world. In their fatwa, the ECFR further added some points which seem to be of specific relevance to Muslims in Europe. For instance, the fatwa stated that there are no ethical objections to directed organ donation and that donor's wishes should be respected in this regard as much as possible. As for the role of the deceased's family, it was clear that the ECFR did not feel the ethical qualms expressed by Govert den Hartogh in the first article of this issue. The fatwa opined that if the deceased did not make up his/her mind before death about organ donation, then the deceased's family has the right to decide. The ECFR went even further by giving the same right to "the authority concerned with the Muslims' interests in non-Muslim countries" if the deceased's family was missing. The ECFR fatwa also indicated that there are no objections, from an Islamic perspective, to the opt-out system. The second fatwa analyzed in this article was issued by the UK Muslim Law (Shariah) Council in 1995.
Different to the ECFR fatwa, this fatwa was much less dependent on the religio-ethical discourse in the Muslim world. The UK fatwa also dedicated much more space to the concept of brain death and argued that this death-criterion is accepted from an Islamic perspective. The fatwa also clearly stated that Muslims may carry donor cards. Like the ECFR fatwa, the UK fatwa expressed no objection to the idea that the deceased's family can decide if the deceased did not have a donor card nor expressed his/her wish before death. Finally, the fatwa stressed that organ donation should be done freely without reward and that trading in organs is prohibited. The third fatwa studied in this article was issued by a Moroccan scholar, Mustafa Ben Hamza, during a conference on "Islam and organ donation" held in 2006 in the Netherlands. This fatwa is characterized by a lengthy discussion of the inter-religious dimension of organ donation; is it possible for a Muslim to donate his/her organs to a non-Muslim? After intriguing argumentation, the fatwa gave a yes-answer for this question and concluded that being ready to receive organs donated by non-Muslims and simultaneously unwilling to donate one's organs to them is neither ethical nor wise and after all does not go in line with the Islamic ethical precepts. The article concludes that Islamic bioethics, as far as it concerns Muslims in Europe, has a distinctively transnational character. In other words, bioethical discourse meant for Muslims in the West is highly interrelated with parallel discourse in the Muslim world. The author also recommends conducting more academic studies to examine the possible impact of these fatwas on Muslims living in Europe (Ghaly 2012).

\section{Concluding remarks}

The overall conclusion of this thematic issue is that organ transplantation is a highly complicated issue from an ethical perspective and thus cannot be reduced to one single ethical value. For instance, the noble desire to help patients who are in need of organ transplantation by making more donated organs available does not justify overlooking other ethical values such as objectivity in communicating information, the requirement of informed consent, providing psychological care whenever needed and doing justice to the religious aspects of the issue. Overlooking such ethical values can be counterproductive on the long run because potential donors might lose their trust in the whole system and thus decline to donate their organs in the future.

Also different articles in this thematic issue highlighted the significance of and the need for conducting more studies on ethnic minorities in Europe and their standpoints towards organ donation. In her article in this thematic issue, Anne Alnaes touched upon this point from an anthropological perspective. She quoted academic studies 
which showed that "Immigrant minority citizens tend to filter information about diet, disease, medication and physical exercise to suit their cultural, ethnic and religious background and culturally formed understandings of body and illness". Alnaes added that other studies argued that "Non-Western ideas about familial duties, individualism and definitions of what constitutes community are differently grounded and impact unexpectedly (according to Western mores and thinking) on choices and judgements" (Alnaes 2012). Sohal Ismail et al. focused on the religious convictions of these ethnic minorities and concluded that "There remains to be a need of more intensified research in this area by including more religious (sub)groups and by more systematically discussing (living) organ donation with respect to religion in order to understand the attitude of ethnic minorities more clearly" (Ismail et al. 2012). The main thesis of Mohammed Ghaly's article is that there is intriguing religio-ethical discourse on organ donation among Muslims in Europe. This means that researchers have sufficient material and infrastructure to study the religious aspects of organ donation among the members of these minorities.

Open Access This article is distributed under the terms of the Creative Commons Attribution Noncommercial License which permits any noncommercial use, distribution, and reproduction in any medium, provided the original author(s) and source are credited.

\section{References}

Alnaes, Anne. 2012. Narratives: An essential tool for evaluating living kidney donations. Medicine, Health Care and Philosophy (this issue).

Den Hartogh, Govert. 2012. The role of the relatives in opt-in systems of postmortal organ procurement. Medicine, Health Care and Philosophy (this issue).

Ghaly, Mohammed. 2012. Religio-ethical discussions on organ donation among Muslims in Europe: An example of transnational Islamic bioethics. Medicine, Health Care and Philosophy (this issue).

Horvat, Lucy, Salimah Shariff, and Amit Garg. 2009. Global trends in the rates of living kidney donation. Kidney International 75: 1088-1098.

Ismail, Sohal, Emma Massey, Annemarie Luchtenburg, Lily Claassens, Willij Zuidema, Jan Busschbach and Willem Weimar. 2012. Religious attitudes towards living kidney donation among Dutch renal patients. Medicine, Health Care and Philosophy (this issue).

Mancuso, Dominick (ed.). 2006. Progress in kidney transplantation. New York: Nova Science Publishers, Inc.

Rady, Mohamed, Joan McGregor and Joseph Verheijde. 2012. Mass media campaigns and organ donation: managing conflicting messages and interests. Medicine, Health Care and Philosophy (this issue).

Schmidt, Volker. 2003. Transplant medicine as borderline medicine. Medicine, Health Care and Philosophy 6: 319-321. 